\title{
Erratum: Preface to special issue on concept lattice and their applications 2008
}

\author{
Radim Belohlavek • Sergei O. Kuznetsov
}

Published online: 23 December 2010

(C) Springer Science+Business Media B.V. 2010

\section{Erratum to: Ann Math Artif Intell DOI 10.1007/s10472-010-9214-x}

The paper "An application of formal concept analysis to semantic neural decoding" by Dominik Maria Endres, Peter Földiák, and Uta Priss can be found in AMAI Volume 57 Issues 3-4 (2009), 233-248.

Article DOI is 10.1007/s10472-010-9196-8.

The online version of the original article can be found at http://dx.doi.org/10.1007/s10472-010-9214-x.

R. Belohlavek

Department of Computer Science, Palacky University,

Olomouc 17, listopadu 12, 77146, Olomouc, Czech Republic

S. O. Kuznetsov $(\varangle)$

Higher School of Economics, Applied Mathematics and Information Science,

Pokrovskii bd., 11, Moscow, 109028, Russia

e-mail: skuznetsov@hse.ru 